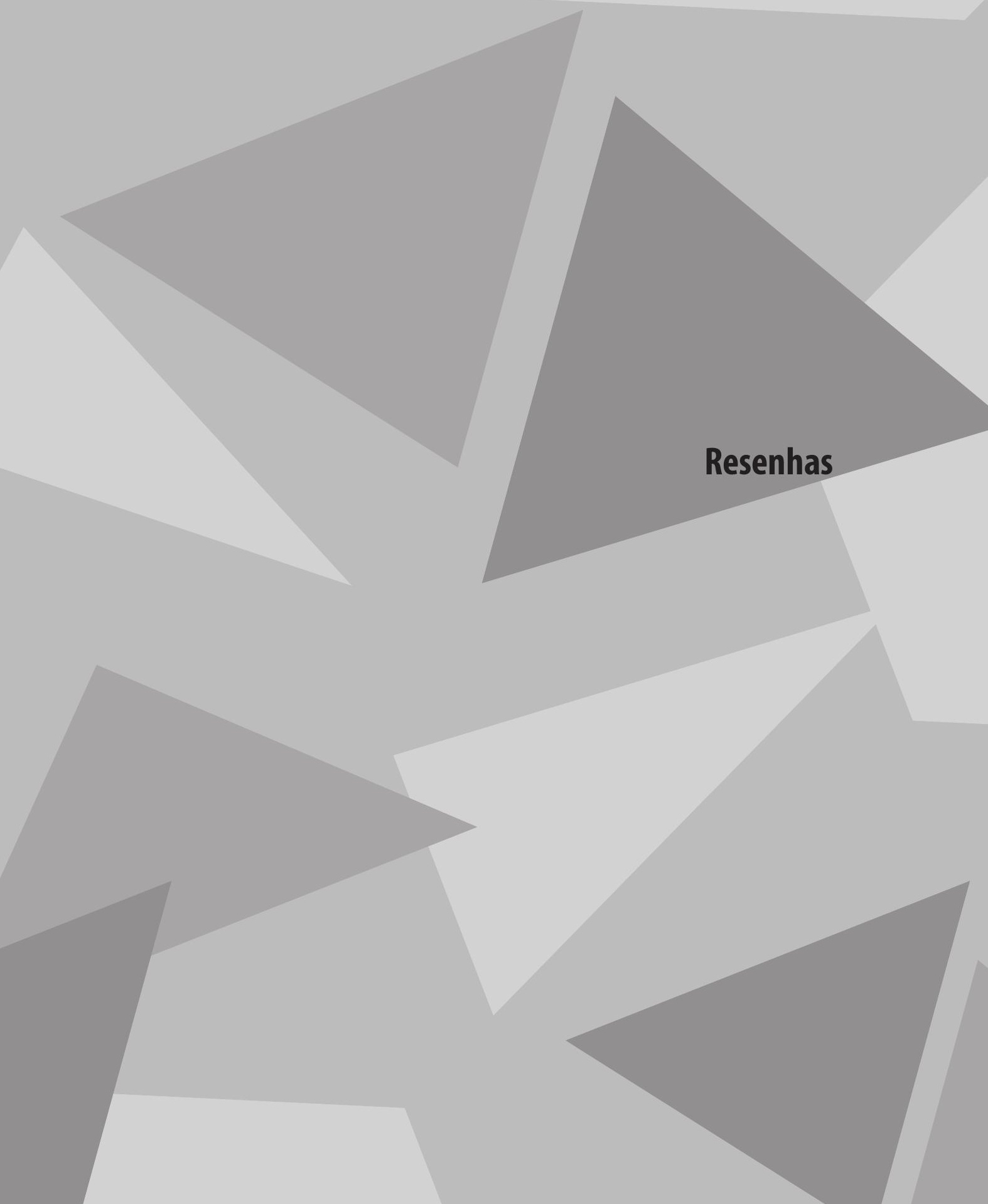





\section{LINGUAGEM \& PRÁTICAS DE SAÚDE: POR UMA INTERAÇÃO ENTRE CAMPOS}

\section{LANGUAGE AND HEALTH PRACTICES: FOR AN INTEGRATION BETWEEN FIELDS}

\section{Alexandre José Cadilhe}

Como a humanização do trabalho em saúde se realiza em ato? Que mecanismos engendram relações de poder na tarefa clínica? Como as relações de gêneros são construídas interacionalmente, e que implicações trazem para o trabalho do médico? Como a linguagem, o discurso, a interação, contribuem para uma compreensão sobre o trabalho em saúde?. Essas e outras questões são discutidas na obra: Humanização. Gênero. Poder. Contribuições dos estudos da fala-em-interação para atenção à saúde, coletânea organizada por Ana Cristina Ostermann e Stela Nazareth Meneghel (Editora Mercado de Letras \& Fiocruz, 2012).

Os tópicos tratados na obra já permitem antever o caráter interdisciplinar do seu tema: trata-se de estudos sobre a linguagem, mais especificamente sobre a fala-em-interação no âmbito das práticas de saúde, com ênfase na consulta clínica. As organizadoras, por sua vez, também apresentam olhares a partir de múltiplos lugares: Ana Cristina Ostermann é linguista aplicada, pesquisadora da Unisinos, doutora em Linguística pela Universidade de Michigan, EUA, com estágio pós-doutoral pela Universidade da Califórnia de Los Angeles, EUA. Stela Nazareth Meneghel é médica, pesquisadora da UFRGS, com doutorado em medicina pela mesma universidade, e estágio pós-doutoral pela UAB, na Espanha. A interação entre ambas permite um olhar ampliado sobre os temas, com interesses tanto aos pesquisadores e profissionais dos estudos aplicados da linguagem, quanto aos da área de saúde e medicina social.

1 Doutor em Estudos da Linguagem pela UFF e mestre em Linguística Aplicada pela UFRJ; docente do curso de Letras da UERJ e da Direção de Pós-Graduação, Pesquisa e Extensão da FESO, em Teresópolis, RJ. alexandre_cadilhe@hotmail.com 
A obra é dividida em cinco partes, compostas no total de nove capítulos. A primeira parte, cujo título é "Introdução e Metodologia", tem por objetivo situar o leitor em que âmbito os estudos sobre humanização, gênero e poder serão discutidos a seguir. O primeiro capítulo tem como título " $\mathrm{Hu}$ manização, Gênero e Poder nos atendimentos à saúde: possibilidades que se apresentam a partir dos estudos da fala-em-interação", de autoria das próprias organizadoras. Nesse artigo, as autoras apresentam uma síntese sobre os estudos acerca dos atendimentos em saúde, cujas preocupações têm-se deslocado do eixo do "que fazer" para "como fazer". Contudo, poucas pesquisas interacionais têm sido realizadas sobre o tema. Alguns dos estudos atuais, no Brasil, partem mais de pesquisas qualitativas na Saúde Pública e na Psicologia Social, de inspiração em Foucault, Deleuze e Gadamer, somente para citar alguns autores.

No mesmo capítulo, Ostermann e Meneghel apontam que, apesar de um reconhecido avanço no tema, há uma escassez de pesquisas de base em dados naturalísticos, ou seja, "dados advindos de situações cotidianas e que acontecem (e aconteceriam) com ou sem a presença de um pesquisador" (p. 14). Tal abordagem é de extrema produtividade para que se tenha a noção de como as políticas de saúde implementadas no país, como as estratégias de humanização, o acolhimento e o cuidado na prática clínica, são efetivamente realizadas em ato. Diante disso, as autoras apresentam os estudos da análise da fala-em-interação como uma possibilidade de compreensão de tais temas. O capítulo é concluído com uma descrição do plano geral da obra.

O segundo capítulo da primeira parte tem como título "Análise da Conversa: o estudo da fala-em-interação", autoria de Ana Cristina Ostermann. Nesse capítulo, Ostermann esclarece como os estudos do discurso, a partir dos fundamentos da Análise da Conversa, podem contribuir para a compreensão de ações sociais situadas, bem como os principais conceitos analíticos utilizados por essa abordagem. Esclarece a autora que tal enfoque parte de uma perspectiva êmica dos dados - ou seja, a partir do que ocorre em situação real, pelo ponto de vista dos participantes. Para que isso seja possível, trabalha-se com a análise da fala enquanto ação social, e como esta se constitui na organização da interação humana. São produtivos os conceitos de turno conversacional e sequencialidade, no que tange à seleção e 
descrição de excertos de fala. A chamada fala-em-interação, enquanto dado de pesquisa, é coletada através da gravação oral ou em vídeo, e transcrita de acordo com normas específicas, de modo a detalhar a expressividade da comunicação oral, como o tom de voz, o tempo e as pausas, as hesitações, etc. Esse registro é relevante porque "o foco da Análise da Conversa não é necessariamente no conteúdo das falas, mas nas ações desempenhadas pelos interagentes e na forma como elas são desempenhadas" (p.41).

Situada a abordagem da pesquisa e sua produtividade para a compreensão das práticas de saúde, tem início a segunda parte da obra, cujo título é "Momentos delicados e poder", constituído por dois capítulos. O primeiro deles tem como autoras Ana Ostermann e Débora Rejane da Rosa, com o título "Do que não se fala: assuntos tabus e momentos delicados em consultas ginecológicas e obstétricas". Nesse capítulo, as autoras investigam interações onde são emergentes situações compreendidas como delicadas, ou seja, quando ocorre uma mudança na orientação interacional dos participantes, resultada de perturbações. Essas perturbações podem ser de duas ordens: quanto aos termos utilizados na consulta (como exemplo, vagina e sexo) ou quanto aos assuntos abordados (como a sexualidade). Ostermann e Rosa, em análise detida de transcrições de consulta ginecológica, observam a dificuldade da paciente para tratar sobre alguns tópicos, bem como o despreparo profissional para lidar com a situação de desconforto da paciente, situações que trazem consequências para o atendimento.

O segundo capítulo da segunda parte tem como título "As relações de poder nas consultas ginecológicas e obstétricas”, de autoria de Ana Cristina Ostermann e Renata Ruy. No estudo apresentado, as relações de poder são compreendidas como exercícios que se dão na e pela fala-em-interação. Nesse sentido, a linguagem é "um meio crucial de desempenhar, construir, manter e resistir relações de poder" (p.66). Em situações clínicas, tais relações emergem nas assimetrias entre médico e paciente. Interacionalmente, a pesquisa aponta essa assimetria principalmente através da sequência "IRA" - iniciação-resposta-avaliação, típica, por exemplo, em aulas tradicionais, onde um docente orienta a interação para avaliar uma resposta de um estudante. A pesquisa desenvolvida por Ostermann e Ruy também aponta tal padrão na relação médico-paciente em consultas ginecológicas e obstétricas, 
utilizado estrategicamente pelos médicos para investigar o conhecimento da paciente acerca do que está sendo orientado na consulta, ainda que nem sempre a paciente sinta-se confortável com o modo pelo qual é abordada neste tipo de interação.

A terceira parte da obra tem como título "Estratégias de Humanização", também composta por dois capítulos. Ambos compartilham de um mesmo pressuposto: a possibilidade de a humanização corresponder ou ser construída a partir de estratégias micro interacionais entre médico e paciente. O primeiro capítulo dessa parte, produzido por Ana Cristina Ostermann e Joseane de Souza, tem como título "As explicações feitas pelas pacientes para as causas dos seus problemas em saúde: como os médicos lidam com isso". Nesta pesquisa, as autoras analisam, a partir das consultas obstétricas e ginecológicas que fazem parte do corpus analisado na obra, o fenômeno interacional da "atribuição", ou "explicações voluntárias que pacientes sobre as causas de seus problemas de saúde e/ou sintomas" (p.85). Tais explicações constituem um fenômeno tácito utilizado pelas pacientes para descrever sintomas, fazer reclamações, acrescentar informações ao responder uma pergunta, etc. Ao médico, por sua vez, caberia validar ou fazer uso dessas atribuições durante a consulta, o que caracterizaria a humanização em ato, segundo as autoras: "dar voz ao(à) paciente e validar seu saber e suas contribuições” (p.97).

O segundo capítulo da terceira parte é intitulado "A Formulação explicitando a compreensão mútua entre médico e paciente: uma forma de humanizar os atendimentos”, por Ana Cristina Ostermann e Caroline Rodrigues da Silva. Nesse estudo, outro fenômeno interacional é trazido à baila: a "formulação", reconhecido como "métodos que os interagentes utilizam para demonstrar explicitamente sua compreensão de partes da interação" (p.100). A formulação é uma prática interacional presente tanto no discurso do médico quanto das pacientes, e que possibilita uma checagem da compreensão de forma colaborativa entre os agentes, ocorrendo em diversas fases do atendimento, e podendo fazer referência ao problema da paciente ou sobre o seu bem-estar em geral, como é observado nos dados analisados pelas autoras.

A quarta parte da obra tem como título "Gênero e Sexualidade", composta por dois artigos que relacionam de forma mais próxima os temas se- 
xualidade, gênero e serviço em saúde. O primeiro capítulo tem como título "Gênero e sexualidade no consultório ginecológico: pressupostos identitários jamais questionados", autoria de Ana Cristina Ostermann e Aline Jaeger. Nessa pesquisa, as identidades são compreendidas não como categorias estáveis e fixas, e sim como algo emergente: "são constituídas, construídas e resistidas por meio de práticas sociais e discursivas, dentre as quais a linguagem tem um papel crucial" (p.120).

A partir desta concepção, Ostermann e Jaeger analisam como médicos e pacientes tornam visível o fazer "heteronormativo", ou seja, a naturalização das práticas heterossexuais como padrão organizador da vida social. Como exemplo, as autoras apresentam micro análises de interações cujos tópicos são os cuidados contraceptivos e o consumo da pílula anticoncepcional, e os pressupostos assumidos pelo médico acerca do planejamento da relação sexual, do relacionamento estável e a preocupação com a gravidez como sendo uma atribuição da mulher. Tais pressupostos podem não condizer com a identidade social da paciente, mas isso parece não ser considerado pelo médico, o que pode ter como efeito uma consulta clínica não atenda às demandas de seus pacientes e, portanto, desumanizada.

O segundo capítulo da quarta parte, "Tensionando identidades de gênero e de sexualidade na fala-em-interação: o colapso discursivo da masculinidade hegemônica”, tem como autoras Mariléia Sell e Ana Cristina Ostermann. Diferentemente dos artigos anteriores, esta pesquisa tem como base dados gerados não em consultas ginecológicas e obstétricas, mas sim consultas de homens com uma psicóloga, prática necessária aos que pretendem submeter-se ao procedimento de vasectomia. Também compartilha, como no último capítulo, uma concepção de gênero não como um estado, mas como algo construído performaticamente nas interações sociais.

No capítulo de Sell e Ostermann, a questão da identidade de gênero no âmbito das masculinidades é investigada através da fala-em-interação, fazendo uso dos procedimentos de Análise das Categorias de Pertença, desenvolvida por Sacks na década de 1960. Nesta perspectiva, tomam-se os mesmos pressupostos da análise da fala-em-interação: o sistema de trocas de turnos, a análise êmica, os dados naturalísticos. Acrescenta-se, ainda, a questão da categorização, enquanto uma "atividade em que os falantes ne- 
gociam, em mútua orientação, comportamentos normativos e expectativas de gênero" (p. 134). Observa-se, assim, nos dados, como homens constroem identidades de masculinidade na consulta com a psicóloga, principalmente em assuntos considerados como delicados na cultura masculina hegemônica: a virilidade e o papel assumido na procriação.

Após a quarta parte, tem início a Conclusão, com o nono e último capítulo da obra: "E então, quais são as contribuições dos estudos da fala-em-interação para a atenção à saúde?", cujas autoras são as organizadoras Stela Nazareth Meneghel e Ana Cristina Ostermann. O propósito do capítulo é justamente apontar possibilidades de respostas para a questão-título do artigo. Para respondê-la, as autoras apresentam uma síntese a respeito da ideia de humanização no âmbito dos serviços em saúde no Brasil. São descritos pelas autoras perspectivas de humanização em caráter interdisciplinar: na Saúde Coletiva, na Filosofia, nas Ciências Sociais, tendo destaque ainda as contribuições de Foucault.

A emergência da necessidade de se pensar a humanização em saúde no Brasil é latente, principalmente quando se reflete sobre as práticas que são consideradas desumanizadoras e os serviços de saúde prestados no país. De acordo com a literatura citada pelas autoras, são indícios de desumanização no atendimento em saúde: a banalização no tratamento dos sujeitos, considerados como "objetos", reduzindo-o muitas vezes a sua doença, o uso excessivo de tecnologias em detrimento à relação, tratamentos diferenciados dependendo da pessoa, etc.

Tantos entraves, contudo, também constituem efeitos da própria formação profissional, segundo Ostermann e Meneghel. Apesar da introdução de temas das ciências humanas nos currículos dos cursos da área de saúde, pouca atenção é dada a tais temas, situação que piora no âmbito do desenvolvimento de habilidades interacionais. Asseveram as autoras a necessidade que tais tópicos constituam um espaço na formação do profissional em saúde, de modo que o aprendizado não se dê somente ao chegar ao campo prático, através da manutenção irrefletida de um "traquejo profissional" observado pelas ações de médicos, preceptores, professores.

Nisto reside uma das contribuições dos estudos da fala-em-interação apresentados na obra: a possibilidade de compreensão das práticas em saú- 
de a partir do ponto de vista dos participantes - perspectiva êmica - tendo como base situações reais de interação, com explicitação das estratégias microinteracionais e discursivas que engendram diferentes efeitos no serviço prestado. Como implicação, aponta outra contribuição: a produtividade do trabalho do linguista aplicado que se dedica a outros campos profissionais, diferentes da sala de aula. Para que a contribuição se dê consubstanciada, torna-se necessário o trabalho interdisciplinar em conjunto com o profissional da outra área em foco, caso que ocorre na obra.

A pesquisa sobre a interação nas práticas de saúde já possui uma tradição em contexto internacional - vide inclusive que a maior parte da bibliografia citada é de origem anglo-americana. No Brasil, contudo, constitui um campo ainda a ser aprofundado. Com exceção de artigos isolados publicados em revistas especializadas no país, a obra organizada por Ostermann e Meneghel representa o pioneirismo nessa área no Brasil, por apresentar de forma didática e esclarecedora aos não iniciados no assunto os pressupostos básicos para a pesquisa da fala-em-interação em práticas sociais. Inclusive um glossário é apresentado ao final, permitindo ao leitor informar-se de forma mais objetiva acerca de termos tratados ao longo dos artigos.

É válido salientar que o título da obra evoca a questão das relações de gênero e a humanização na saúde. Contudo, somente um capítulo é dedicado aos estudos sobre o campo da masculinidade, outra área escassa de estudos no viés dos estudos da fala-em-interação. Os demais discutem o gênero do ponto de vista da feminilidade, principalmente em consultas no campo da ginecologia e obstetrícia. Não são apontados outros estudos além dessa área de serviço de saúde, o que encerra por situar possibilidades de humanização somente nesse âmbito - excetuando novamente o único capítulo dedicado à masculinidade, cuja consulta analisada foi da área de psicologia. Pesquisas que analisem a micropolítica da humanização em outros serviços de saúde são de grande valia para o enriquecimento de tal campo de estudos no Brasil.

A obra é uma referência aos estudantes e pesquisadores dos estudos da linguagem, especialmente dos cursos de graduação e pós-graduação em Letras e Linguística, cuja preocupação centra-se nos usos da linguagem em práticas de trabalho. Também é de interesse aos profissionais da saúde, incluindo estudantes de graduação e pós-graduação em Medicina, Enferma- 
gem e Psicologia, considerando a especial contribuição ao tema sobre humanização nos serviços de saúde.

Recebido em: 13 de junho de 2013

Aceito em: 15 de julho de 2013 